\title{
The Effect of Environmental Enrichment with Autistic-like Behavior Symptoms on a Rattus norvegicus Model
}

\author{
Amel Yanis ${ }^{1 *}$, Yanwirasti Yanwirasti ${ }^{2}$, Nurmiati Amir $^{1}$, Ekowati Handharyani $^{3}$ \\ ${ }^{1}$ Department of Psychiatry, Faculty of Medicine, Universitas Andalas, Padang, Indonesia; ${ }^{2}$ Department of Anatomy, Faculty \\ of Medicine, Universitas Andalas, Padang, Indonesia; ${ }^{3}$ Department of Pathological Anatomy, Faculty of Veterinary Medicine, \\ Bogor Agricultural University, Bogor, Indonesia
}

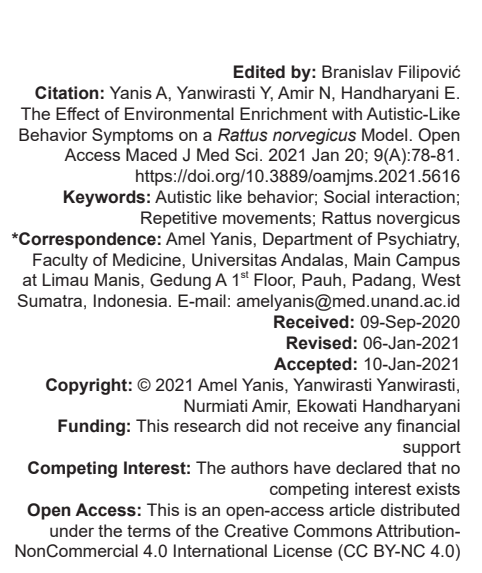

Abstract

AIM: The aim of this study was to investigate the effect of environmental enrichment with autistic-like behavior symptoms on a Rattus norvegicus model.

METHODS: The post-test control only group design is used in this study. The study sample is baby of Rattus norvegicus Sprague Dawley strain who were born to cows who gave birth for the $1^{\text {st }}$ time and children from cows who had been injected with valproic acid (VPA) who gave birth for the $1^{\text {st }}$ time. This study has been divided into three groups, namely, negative control, positive control, and intervention: the negative control group; the VPA without enrichment as positive control; and the VPA group with enrichment as intervention group. One-way ANOVA tests were used to data analysis. Data are processed using SPSS version 23.0.

RESULTS: This study showed that the mean of social interaction in the negative control group was $359.11 \pm 39.33$ $\mathrm{s}$ higher than the positive control, namely, $182.00 \pm 35.80 \mathrm{~s}$ and $244.56 \pm 19.06 \mathrm{~s}$ for intervention. The mean of repetitive movement in the negative control group was $48.00 \pm 9.03 \mathrm{~s}$ lower than the positive control, namely, 212.11 $\pm 41.43 \mathrm{~s}$ and intervention $160.00 \pm 18.91 \mathrm{~s}$. There has been an influence of environmental enrichment with social interaction and repetitive movements on a Rattus norvegicus model $(p<0.05)$.

CONCLUSION: This study confirmed that there has been an influence of environmental enrichment with socia interaction and repetitive movements on a Rattus norvegicus model.

\section{Introduction}

Autism spectrum disorder (ASD) is a serious problem in the field of child psychiatry, because this severe developmental disorder has experienced a sharp increase in prevalence in a short time. One of the non-genetic factors that play a role in the occurrence of ASD is exposure to valproic acid (VPA). The use of VPA during the first trimester of pregnancy when the neural tube has not closed increases the risk of ASD in the child. Prenatal VPA exposure in experimental animals was associated with a 7-fold increased risk of developing ASD [1], [2].

Until now, there has not been found a drug that can definitively improve the core symptoms of ASD, namely, deficit in social interaction, deficit in communication, and repetitive behavior. This disorder is a neurodevelopmental disorder that occurs at a young age. As it is known that neurons at a young age are susceptible to drug side effects, the Food and Drug Administration (FDA) recently approved risperidone and aripiprazole for use in treating aggressive ssesymptoms and self-injury in children with ASD. The Food and Drug Administration (FDA) recently approved risperidone and aripiprazole for use in treating aggressive ssesymptoms and self-injury in children with ASD. The non-psychopharmaceutical approach is in the form of occupational therapy and speech therapy to improve reciprocal social relations, language, and communication. So far, the interventions that can be given to ASD are new to the point of positively affecting developmental trajectories to steer individuals toward more neurotypical states [3], [4].

A study reported that environmental enrichment can improve autistic-like behavior (ALB) symptoms in the form of social deficits, stereotypical movements, and anxiety in mice exposed to VPA [5]. Environmental enrichment effectively improves cognition and emotional regulation [6]. This occurs through epigenetic modulation of NMDA receptormediated pathway (NMDAR) and activation of activity-dependent CaMKII [7]. NMDAR activation stimulates the release of brain-derived neurotrophic factor (BDNF), which can induce neuronal protein synthesis through activation of the TrkB synaptic receptor [8].

The aim of this study was to investigate the effect of environmental enrichment with autistic-like behavior symptoms on a Rattus norvegicus model. 


\section{Materials and Methods}

\section{Study design and research sample}

The post-test control only group design is used in this study. The study sample is baby of Rattus norvegicus Sprague Dawley strain who were born to cows who gave birth for the $1^{\text {st }}$ time and children from cows who had been injected with valproic acid (VPA) who gave birth for the $1^{\text {st }}$ time.

\section{Operational definition}

Environmental enrichment was by providing objects that stimulate visuospatial, motor, cognitive, somatosensory (wheels, small balls, blocks of various sizes, elbow tunnels, and seesaw) in the mice cage. ALB symptoms can be seen where the behavior of decreasing social interaction is the time spent by experimental animals interacting with other animals $<50 \%$ of the time of observation and repetitive movement behavior, namely, self-grooming, jumping around, circling, or stereotypically sniffing - sniff a location or object more than $2 \mathrm{~min}$ from the time of observation.

\section{Research procedures}

This study has been divided into three groups, namely, negative control, positive control, and intervention: the negative control group; the VPA without enrichment as positive control; and the VPA group with enrichment as intervention group. On day 12.5 of pregnancy, intraperitoneal VPA $500 \mathrm{mg} / \mathrm{kg}$ which had been dissolved in normal saline was injected into $1.5 \mathrm{ml}$ to each cow in the positive control and intervention groups. Each cow mice gave birth to at least five cubs and a maximum of seven chicks. At 2 weeks of age, the positive control group was assessed for ALB symptoms (social interaction and repetitive movements). The puppies showing ALB symptoms were randomly taken nine for the positive control group and nine for the intervention group. The puppies of the intervention group were kept in a cage with environmental enrichment. Nine mice in group negative control were also taken randomly. All pups were reared and their mothers in individual cages until 3 weeks of age. Each pup from each cage was marked with picric acid on the nape, back, and base of the tail. When the pups were 21 days old, the ALB behavior was again observed in the form of social interaction and repetitive movements.

\section{Data analysis}

The research results are tabulated and presented in the table. The hypothesis test used depends on the normality and homogeneity test of the data obtained. Data analysis was performed using the ANOVA test and continued with the post hoc Bonferroni test. Data are processed using SPSS version 23.0.

\section{Results}

Research has been conducted to determine the effect of environmental enrichment with autisticlike behavior symptoms on a Rattus norvegicus model. Normality tests were carried out using Shapiro-Wilk $(\mathrm{n}<50)$ on autistic-like behavior symptoms data on a Rattus norvegicus model (Table 1).

\section{Table 1: Data normality test}

\begin{tabular}{lll}
\hline Variables & Group & p value \\
\hline Social interaction (seconds) & Negative control & $0.364^{*}$ \\
& Positive control & $0.957^{*}$ \\
Repetitive movement (seconds) & Intervention & $0.051^{*}$ \\
& Negative control & $0.390^{*}$ \\
& Positive control & $0.170^{*}$ \\
& Intervention & $0.434^{*}$ \\
\hline${ }^{*} \mathrm{p}>0.05$, normally distributed data. &
\end{tabular}

Based on Table 1, it is known that the normality test results of social interaction data and repetitive movements are normally distributed $(p>0.05)$. Then, the data analysis was continued using parametric statistics.

The effect of environmental enrichment on social interactions can be seen in Table 2 .

Table 2: The effect of environmental enrichment on social interactions

\begin{tabular}{llll}
\hline Groups & $\mathrm{n}$ & Social interaction (seconds) (Mean \pm SD) & $\mathrm{p}$-value \\
\hline Negative control & 9 & $359.11 \pm 39.33$ & $<0.001^{*^{\mathrm{a}}}$ \\
Positive control & 9 & $182.00 \pm 35.80$ & \\
Intervention & 9 & $244.56 \pm 19.06$ & \\
\hline${ }^{*} \mathrm{p}<0.05$. a, one-way ANOVA test. & &
\end{tabular}

Table 2 found that the mean of social interaction in the negative control group was 359.11 $\pm 39.33 \mathrm{~s}$ higher than the positive control, namely, $182.00 \pm 35.80 \mathrm{~s}$ and $244.56 \pm 19.06 \mathrm{~s}$ for intervention. Based on the results of statistical tests using the oneway ANOVA test, it is known that there is a significant effect of environmental enrichment on social interaction $(p=<0.001, p<0.05)$.

Boxplots of social interaction in seconds can be seen in Figure 1.

Figure 1 shows that the average social interaction in the negative control group was higher than the positive control and intervention.

Significant social interactions based on the group, the post hoc Bonferroni follow-up test was carried out (Table 3 ).

Table 3 found that significant social interactions occurred in positive control and treatment $(p<0.05)$.

The effect of environmental enrichment on repetitive movements can be seen in Table 4 . 


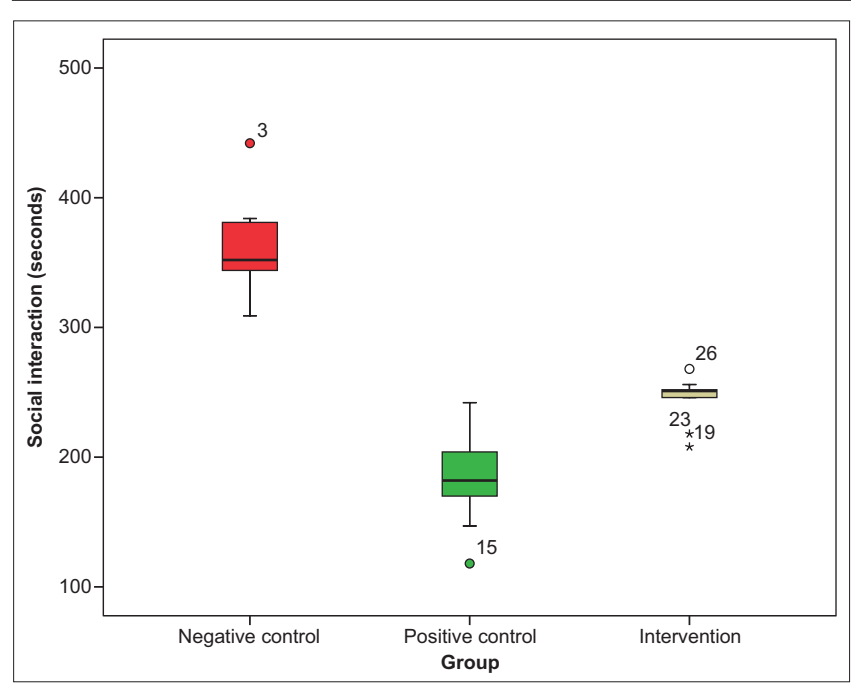

Figure 1: Boxplots social interaction in seconds

Table 3: Significant social interactions by group

\begin{tabular}{llll}
\hline Group & Negative control & Positive control & Intervention \\
\hline Negative control & - & $<0.001^{*}$ & $<0.001^{*}$ \\
Positive control & $<0.001^{*}$ & - & $0.001^{*}$ \\
Intervention & $<0.001^{*}$ & $0.001^{*}$ & - \\
\hline${ }^{*} \mathrm{p}<0.05$ signifikan penurunan. & &
\end{tabular}

Table 4 found that the mean of repetitive movement in the negative control group was $48.00 \pm$ $9.03 \mathrm{~s}$ lower than the positive control, namely, 212.11 $\pm 41.43 \mathrm{~s}$ and intervention $160.00 \pm 18.91 \mathrm{~s}$. Based on the results of statistical tests using the one-way ANOVA test, it is known that there is a significant effect of environmental enrichment on repetitive movement $(p \leq 0.001, p<0.05)$.

Table 4: The effect of environmental enrichment on repetitive movements

\begin{tabular}{lcll}
\hline Group & $\mathrm{n}$ & Repetitive movements (seconds) (Mean \pm SD) & $\mathrm{p}$-value \\
\hline Negative control & 9 & $48.00 \pm 9.03$ & $<0.001^{\text {*a }}$ \\
Positive control & 9 & $212.11 \pm 41.43$ & \\
Intervention & 9 & $160.00 \pm 18.91$ & \\
\hline${ }^{*} \mathrm{p}<0,05$. ${ }^{\text {o one-way ANOVA test. }}$ & &
\end{tabular}

Boxplots of repetitive movements in seconds can be seen in Figure 2.

Figure 2 shows the mean of repetitive movement in the negative control group lower than the positive control and interventions.

The significance of repetitive movements based on the group, the post hoc Bonferroni follow-up test was performed (Table 5).

Table 5: Significant repetitive movements by group

\begin{tabular}{llll}
\hline Group & Negative control & Positive control & Intervention \\
\hline Negative control & - & $<0.001^{*}$ & $<0.001^{*}$ \\
Positive control & $<0.001^{*}$ & - & $0.001^{*}$ \\
Intervention & $<0.001^{*}$ & $0.001^{*}$ & - \\
\hline${ }^{*} \mathrm{p}<0.05$ significant & & &
\end{tabular}

Table 5 found that significant repetitive movements occurred in positive and treatment controls $(p<0.05)$.

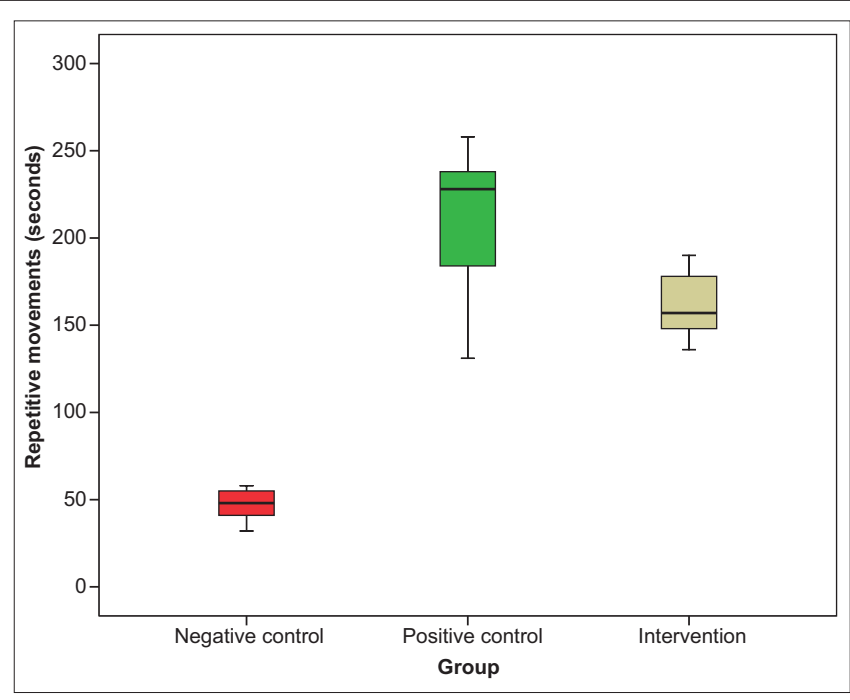

Figure 2: Boxplots of repetitive movements in seconds

\section{Discussion}

The results of this study found that there is an increase in social interaction and a decrease in the duration of repetitive movements in mice that experience ALB and get environmental enrichment compared to those without environmental enrichment.

A study reported that environmental enrichment can improve autistic-like behavior (ALB) symptoms in the form of social deficits, stereotypical movements, and anxiety in mice exposed to VPA [5]. Environmental enrichment effectively improves cognition and emotional regulation [6]. This occurs through epigenetic modulation of NMDA receptormediated pathway (NMDAR) and activation of activitydependent CaMKII [7]. NMDAR activation stimulates the release of brain-derived neurotrophic factor (BDNF), which can induce neuronal protein synthesis through activation of the TrkB synaptic receptor [8].

Stimulation through touch and olfactory is meaningful for the improvement of atypical social behavior and poor social communication skills in children with ASD. The previous study has reported that physical activity can increase BDNF gene expression in the hippocampus. Overall BDNF strengthens excitatory (glutamatergic) synapses and reduces inhibitory synapses (GABAergic). BDNF also enhances neurogenesis [9]. Thus, intervention with environmental enrichment is expected to correct the imbalance between excitatory and inhibitory synapses, which is one of the pathomechanisms thought to underlie clinical symptoms in ASD. Other researcher reported that environmental enrichment could improve ALB symptoms in the form of social deficits, stereotypical movements, and anxiety in mice exposed to VPA 75]. 


\section{Conclusion}

This study has confirmed that there is an increase in social interaction and a decrease in the duration of repetitive movements in mice that experience ALB and get environmental enrichment compared to those without environmental enrichment.

\section{References}

1. Ganz ML. The lifetime distribution of the incremental societal costs of autism. Arch Pediatr Adolesc Med. 2007;161(4):343-9. https://doi.org/10.1001/archpedi.161.4.343

PMid: 17404130

2. Gräff J, Tsai LH. Histone acetylation: Molecular mnemonics on the chromatin. Nat Rev Neurosci. 2013;14(2):97-111. https://doi. org/10.1038/nrn3427

PMid:23324667

3. Lord C, Jones RM. New strategies and findings for behavioral interventions in autism spectrum disorders. Ann NY Acad Sci. 2013;1304:70-6. https://doi.org/10.1111/nyas.12311 PMid:24279894

4. Rogers SJ, Estes A, Lord C, Vismara L, Winter J, Fitzpatrick A, et al. Effects of a brief early start denver model (ESDM)-based parent intervention on toddlers at risk for autism spectrum disorders: A randomized controlled trial. J Am Acad Child Adolesc Psychiatry. 2012;51(10):1052-65. https://doi.org/10.1016/j. jaac.2012.08.003

PMid:23021480

5. Schneider T, Turczak J, Przewłocki R. Environmental enrichment reverses behavioral alterations in rats prenatally exposed to valproic acid: Issues for a therapeutic approach in autism. Neuropsychopharmacology. 2006;31(1):36-46. https:// doi.org/10.1038/sj.npp.1300767

PMid:15920505

6. Hannan A. Environmental enrichment and brain repair: Harnessing the therapeutic effects of cognitive stimulation and physical activity to enhance experience-dependent plasticity. Neuropathol Appl Neurobiol. 2014;40(1):13-25. https://doi. org/10.1111/nan.12102

PMid:24354721

7. Dawson G, Toth K, Abbott R, Osterling J, Munson J, Estes A, et al. Early social attention impairments in autism: Social orienting, joint attention, and attention to distress. Dev Psychol. 2004;40(2):271-83. https://doi.org/10.1037/0012-1649.40.2.271 PMid:14979766

8. Kelleher RJ, Bear MF. The autistic neuron: Troubled translation? Cell. 2008;135(3):401-6. https://doi.org/10.1016/j. cell.2008.10.017

PMid:18984149

9. Binder DK, Scharfman HE. Brain-derived neurotropic factor. Growth Factors. 2004;22(3):123-31.

PMid:15518235 